\title{
De huisartsenpraktijk en COVID-19
}

Half maart brak de mitigatiefase aan in de strijd tegen COVID-19 en veranderde het werk in veel Nederlandse huisartsenpraktijken totaal, met grote regionale verschillen. $\mathrm{H} \& \mathrm{~W}$-fotograaf Margot Scheerder bracht begin april in beeld hoe diverse huisartsenpraktijken in Nederland hiermee omgaan.
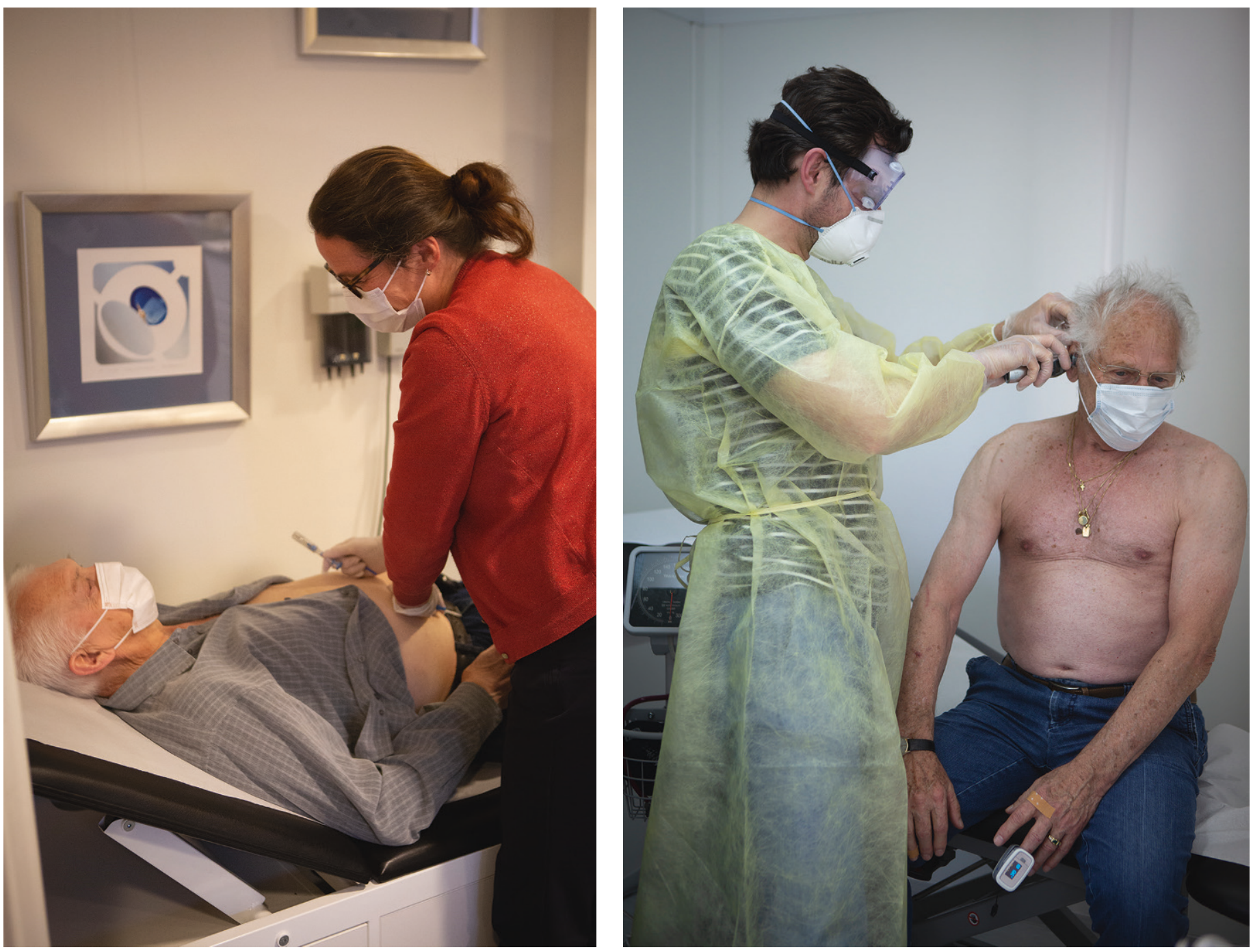

'Gewone' patiënten en huisartsen dragen tijdens het spreekuur een mondkapje [foto links, Muiden]. Bij patiënten die coronaverdacht zijn, draagt de huisarts naast een mondkapje ook een beschermend schort met lange mouwen, handschoenen en een veiligheidsbril [foto rechts, Burgum]. 


\section{De dagpraktijk}

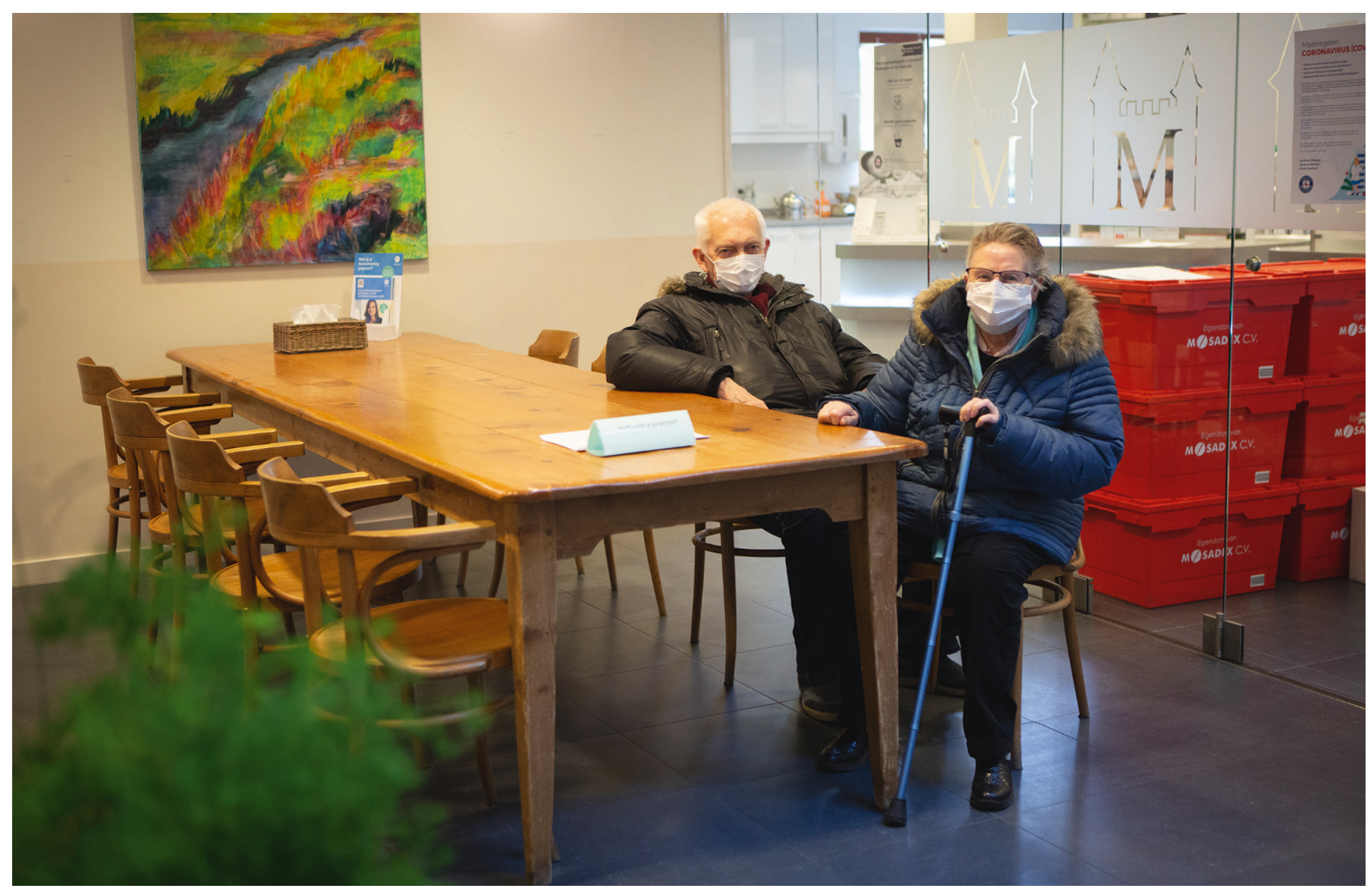

In de wachtkamer dragen niet-coronaverdachte patiënten mondkapjes [Muiden].

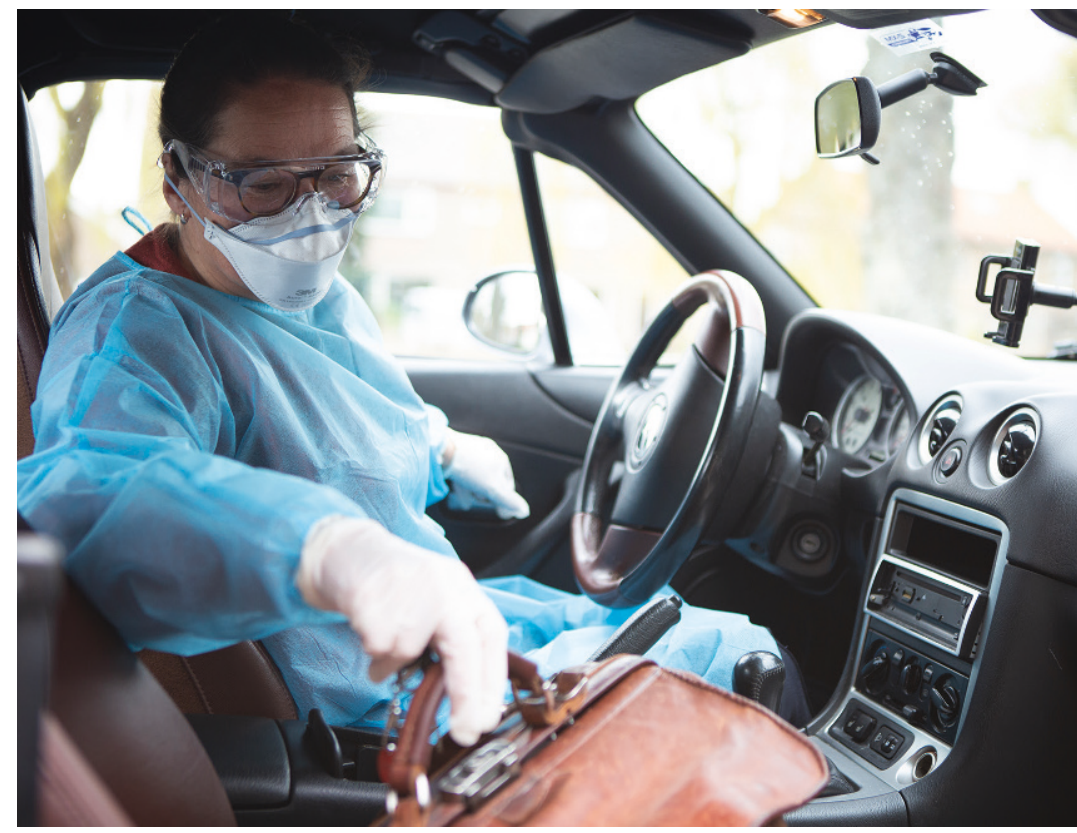

Huisarts Jantine de Maat onderweg naar een coronaverdachte patiënt.

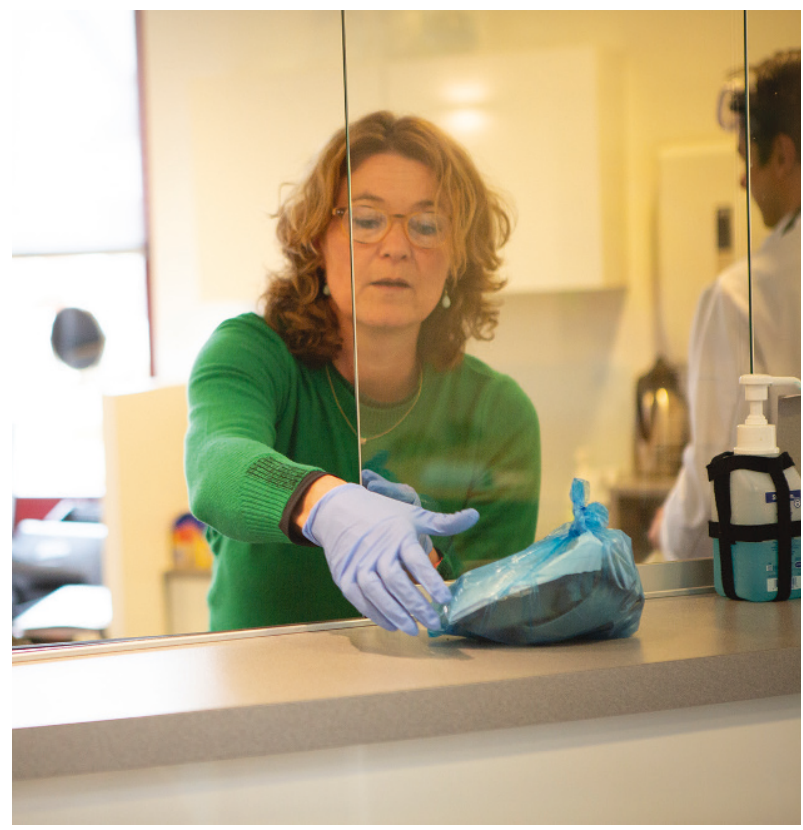

De assistente pakt een in plastic verpakt urinesample met handschoenen aan. 

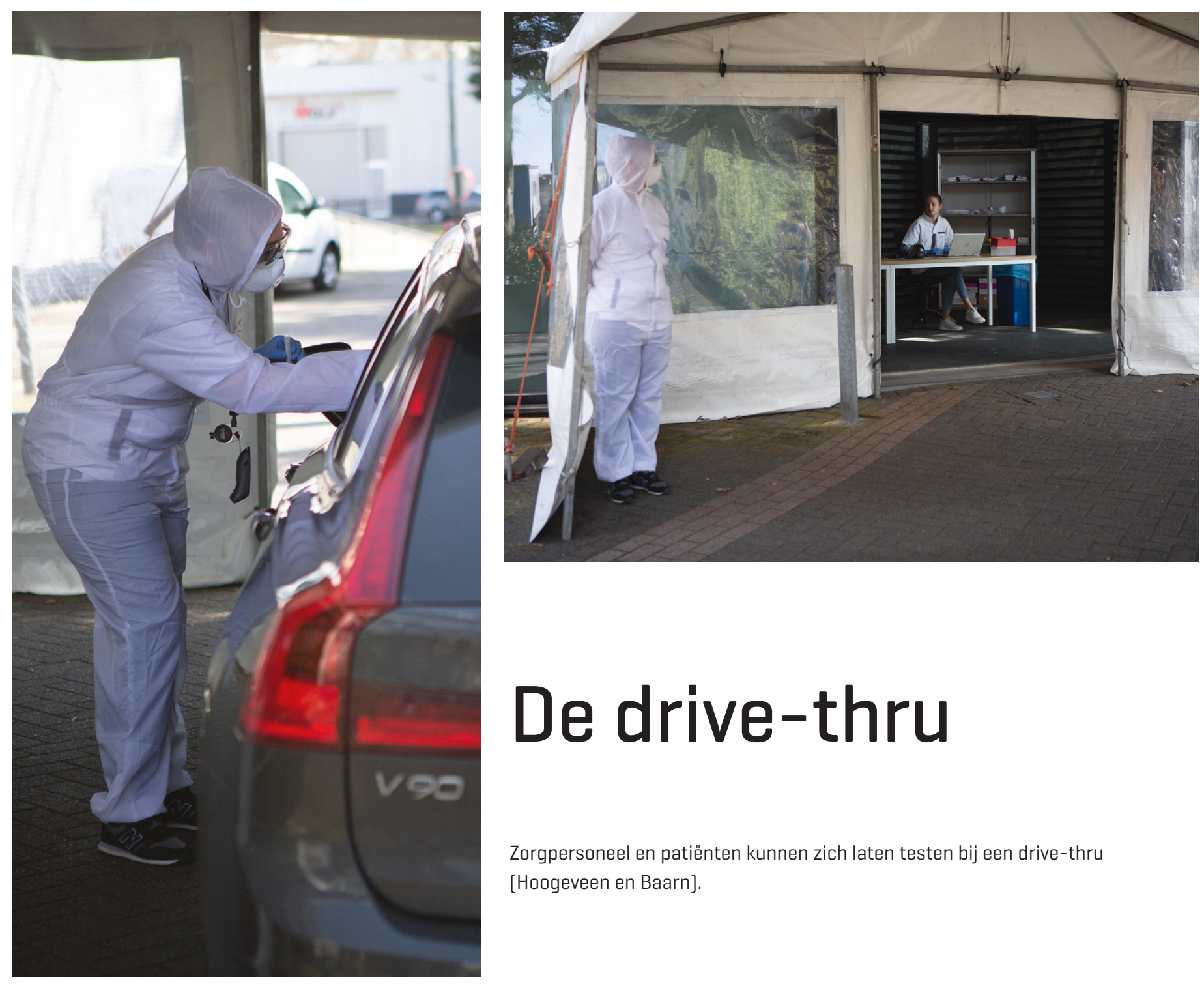

\section{De drive-thru}

Zorgpersoneel en patiënten kunnen zich laten testen bij een drive-thru [Hoogeveen en Baarn].

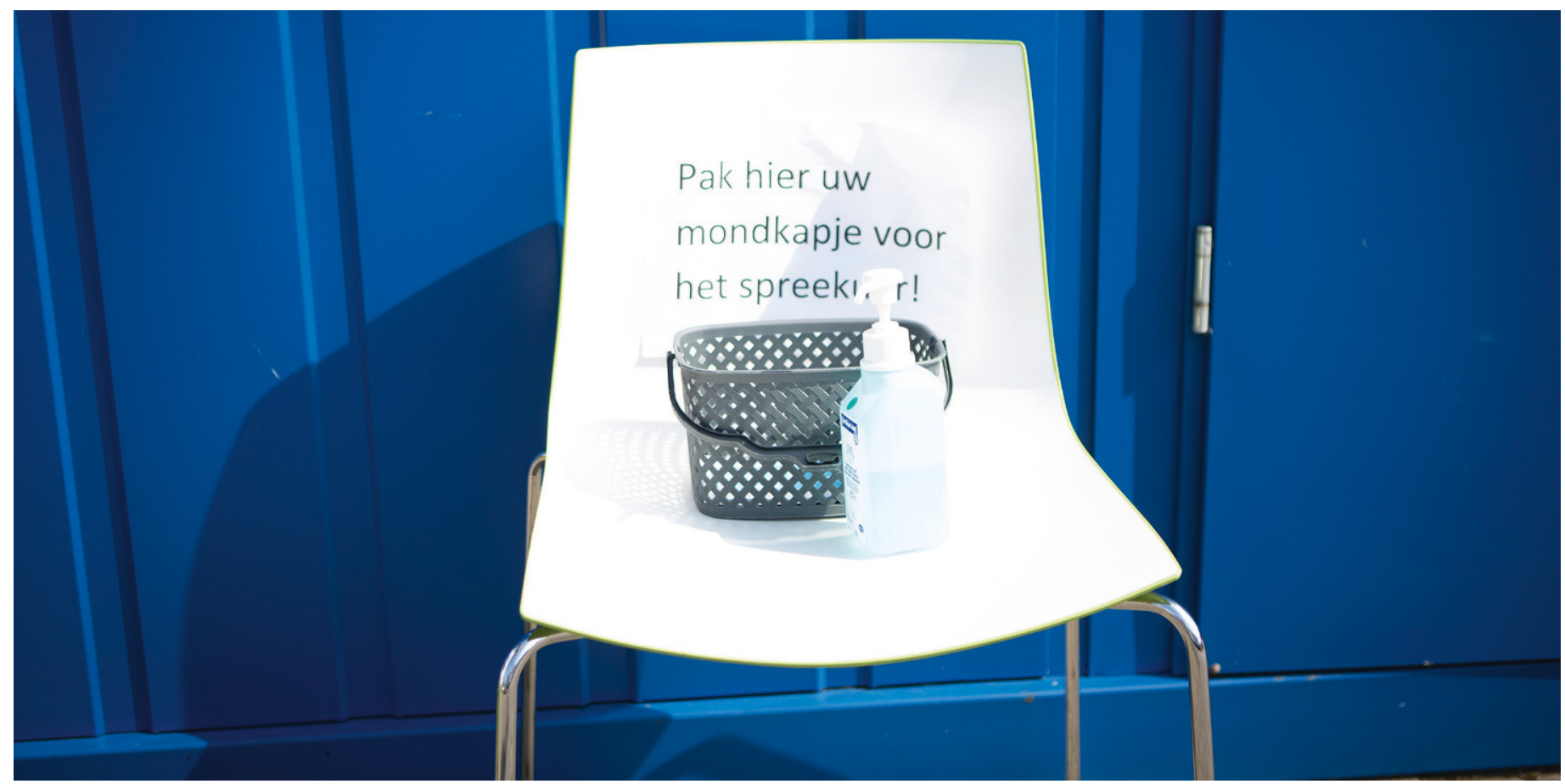




\section{Spreekuur in een container}

Coronaspreekuur in een container die naast de praktijk op het parkeerterrein staat [Burgum].
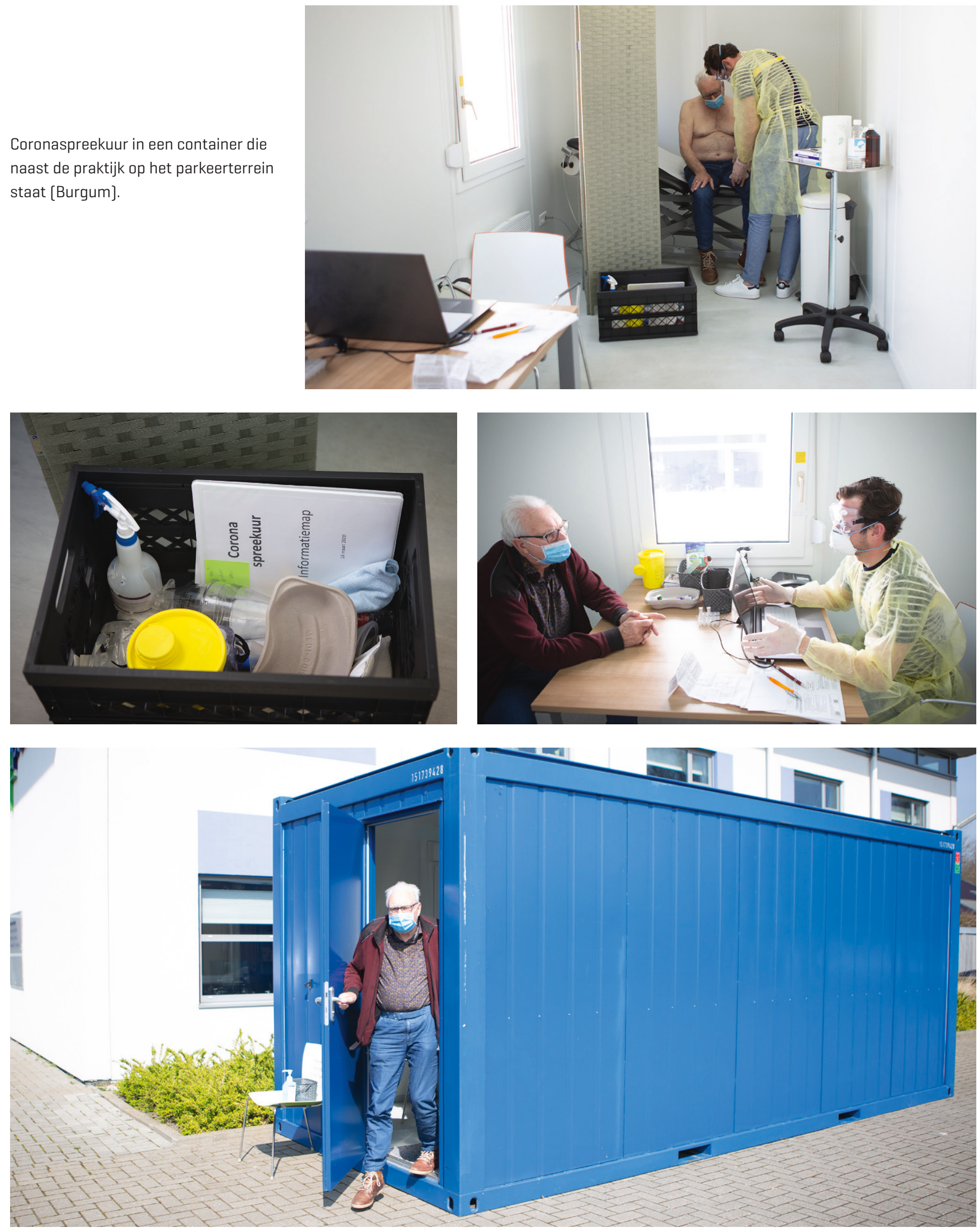


\section{De hoestpoli}
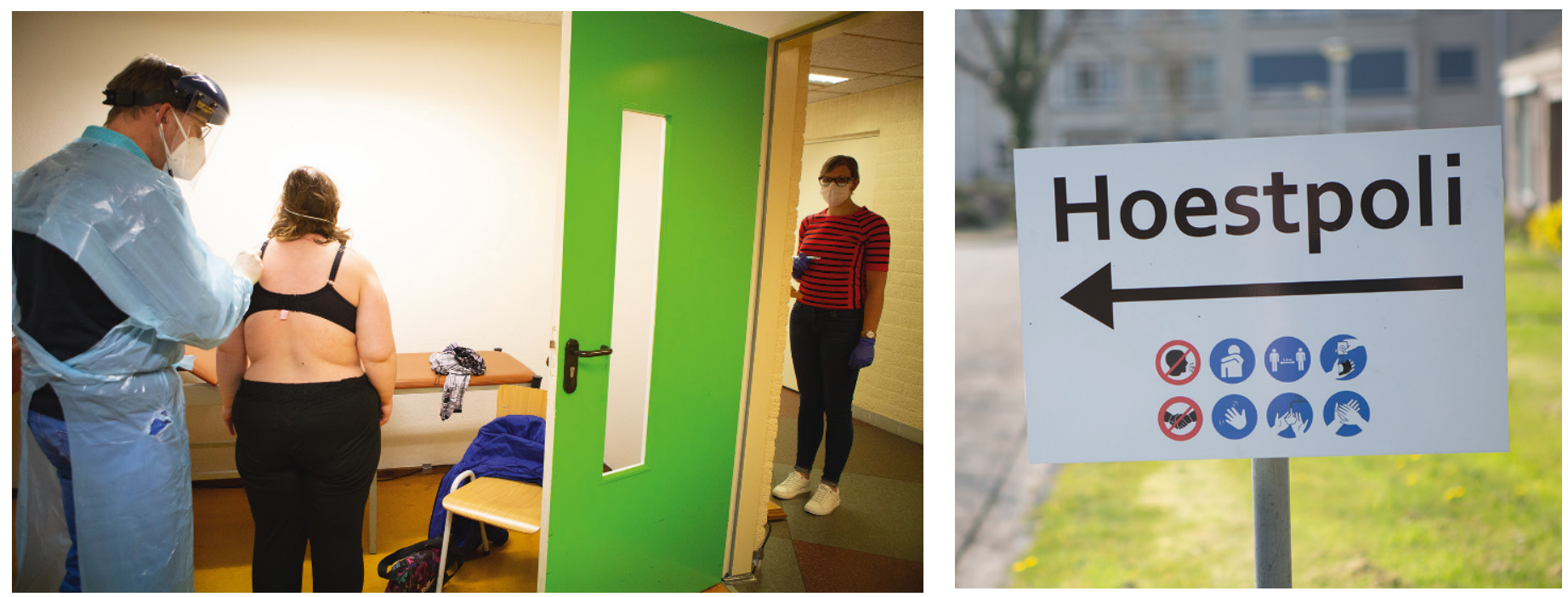

Coronaspreekuur in een oud verpleeghuis [Oosterwolde, Fr.]. Foto boven: de assistente voert op de gang de gegevens in het HIS in. Foto's onder: na ieder onderzoek moet alles gereinigd worden. Een boterhamzakje gaat om de saturatiemeter om besmetting te voorkomen.
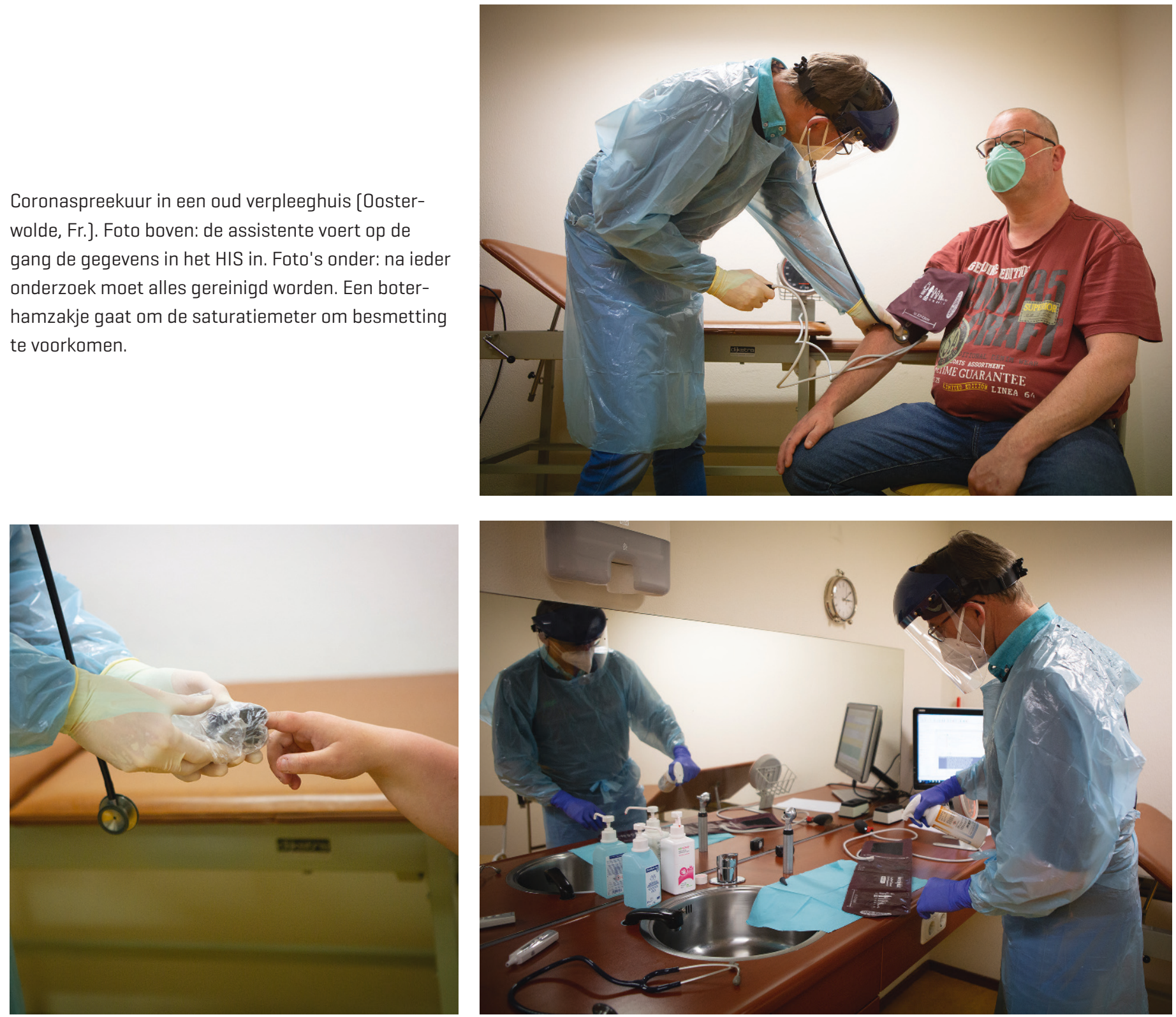


\section{Spreekuur in een sporthal}
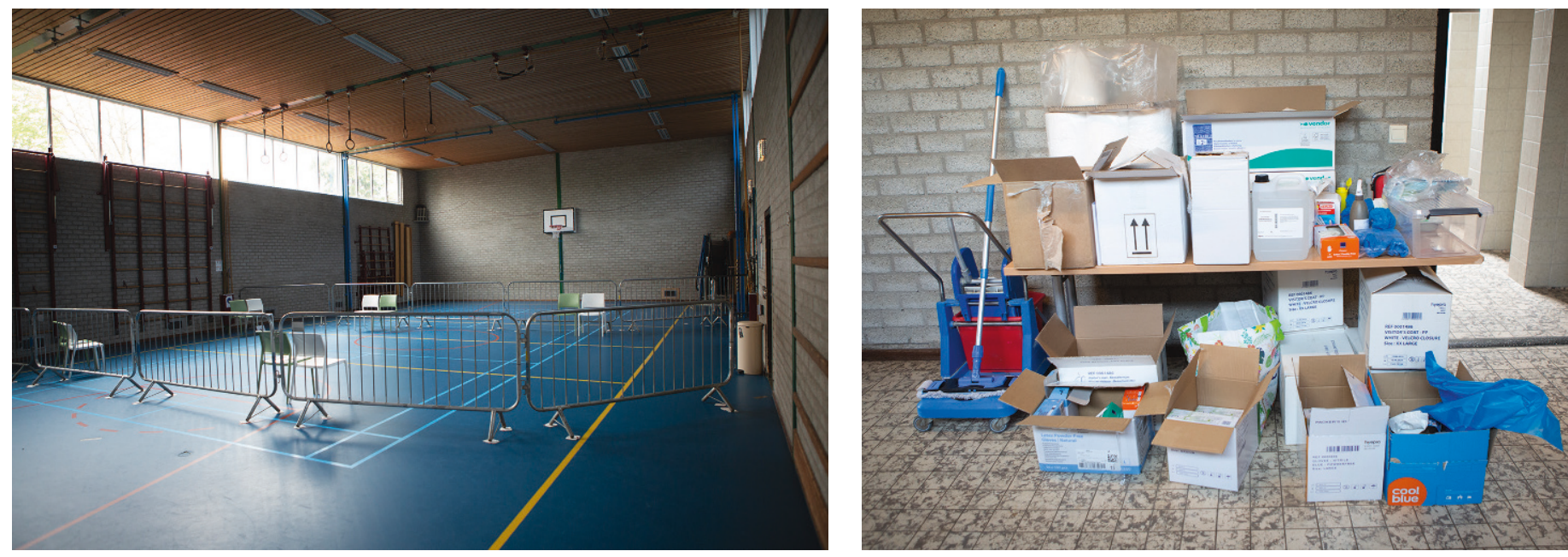

Huisartsen houden coronaspreekuur in een sporthal waar zes spreekkamers gerealiseerd kunnen worden [Oisterwijk]. Door het werken met verschillende HISsen schrijven huisartsen alles ouderwets op papier, maken er een foto van en delen deze via de app Siilo met de huisarts van de patiënt.
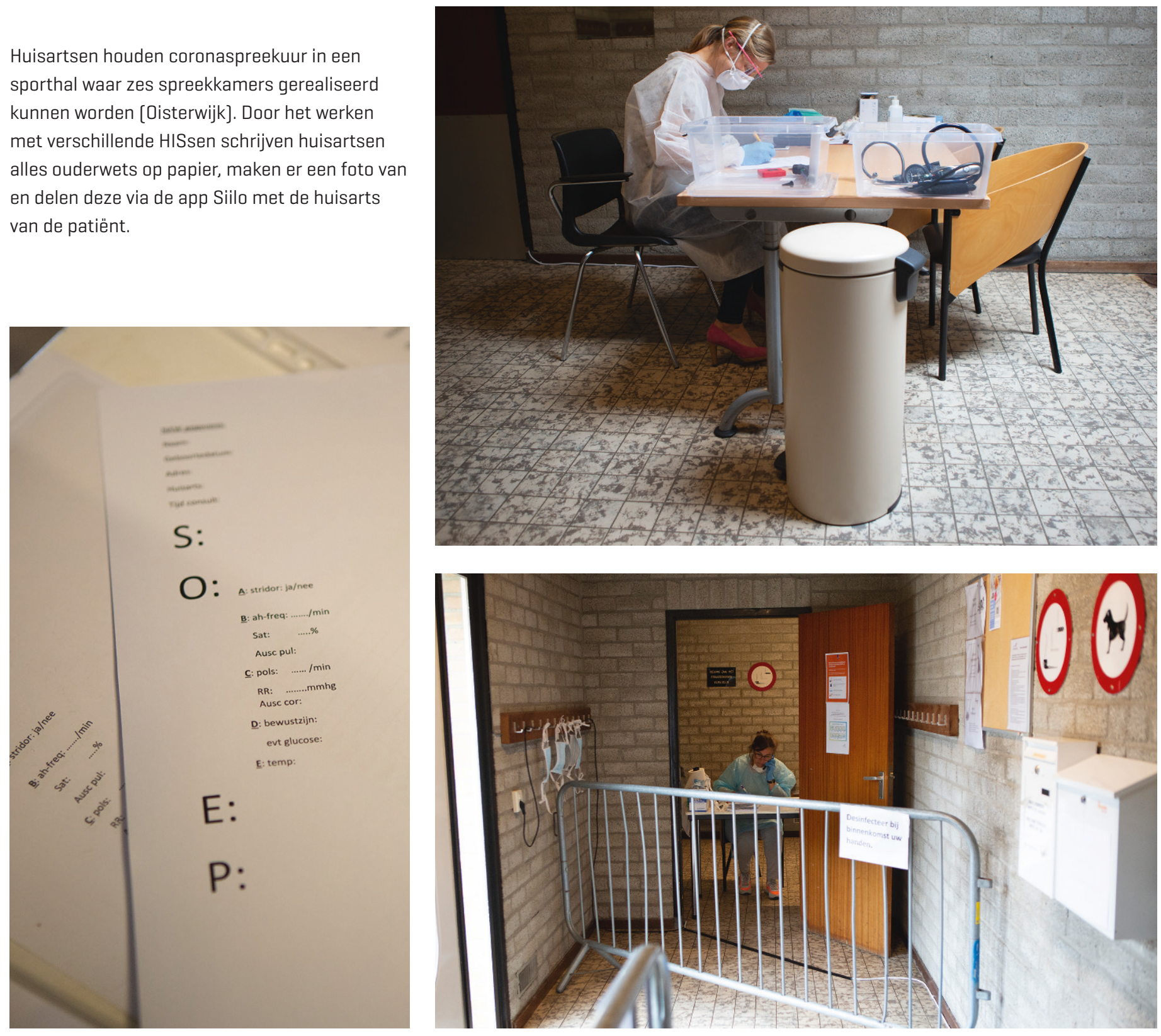